\title{
CATENA(HEXA-AQUA-COBALT(II) TETRA-AQUA-(M_-1,2,4,5-BENZENECARBOXYLATO-O,O') -COBALT(II) HYDRATE): A NEW SYMMETRY FOR AN OLD POLYMORPHIC PHASE
}

\author{
ANA MARÍA ATRIA, ${ }^{a *}$ MARÍA TERESA GARLAND ${ }^{b}$ AND RICARDO BAGGIO ${ }^{c}$ \\ ${ }^{a}$ Facultad de Ciencias Químicas y Farmacéuticas, Universidad de Chile, \\ Casilla 233, Santiago, Chile. \\ ${ }^{b}$ Departamento de Física, Facultad de Ciencias Físicas y Matemáticas, Universidad de Chile, Santiago de Chile, Chile. \\ 'Departamento de Física, Centro Atómico Constituyentes, Comisión Nacional de Energía Atómica, Buenos Aires, Argentina
}

(Received: August 14, 2012 - Accepted: October 5, 2012)

\begin{abstract}
The title cobalt complex $\left(\mathrm{C}_{10} \mathrm{H}_{38} \mathrm{Co}_{2} \mathrm{O}_{26}\right)$ consists of $\left[\mathrm{Co}\left(\mathrm{H}_{2} \mathrm{O}\right)_{4}\left(\mathrm{C}_{10} \mathrm{H}_{2} \mathrm{O}_{8}\right)\right]^{2-}$ anionic chains, balanced by $\left[\left(\mathrm{Co}\left(\mathrm{H}_{2} \mathrm{O}\right)_{6}\right]^{2+}\right.$ cations and eight solvato water molecules, some of which are disordered. The chains are formed by $\mathrm{Co}\left(\mathrm{H}_{2} \mathrm{O}\right)_{4}$ "beads" threaded by fully deprotonated benzenecarboxylato anions binding in a stretched, trans fashion, and they are linked by H-bonds into a 2D structure. The cationic groups and solvato water molecules form a second kind of 2D arrays, "sanwiched" by the latter ones and linking the lot into a 3D structure through a very complex H-bonding interaction scheme. The structure presents a very conspicuous pseudo symmetry, and it appears to be a slight polymorphic modification of an already published isologue of identical formulation but with the higher symmetry properly attained, in a volume half as large. The slight differences between both structures seems to reside mainly in the (disordered) solvates, as suggested by the overlap of both models.
\end{abstract}

Keywords: crystal structure, polymorph, cobalt.

\section{INTRODUCTION}

Crystal structures of diverse dimensionality built up around metal centres and bridged by carboxylate linkers are extremely interesting systems from a structural point of view, due to the topologic variations they can give rise to [1] as well as for practical aspects, viz., their potential applications in medicine, chemical separation and heterogeneous catalysis, and occasionally due to their eventual electronic or magnetic properties $[2,3]$. The presence of two potentially coordinating $\mathrm{O}$ atoms in the carboxylate group usually renders these compounds particularly stable at the same time that they can assume different coordination modes to metallic centres (syn-syn, syn-anti and antianti), which may lead to a variety of structural types. In general, it appears that syn-syn conformations lead to binuclear compounds, while the remaining conformations favour polymeric entities [1, 4-7].

In particular the benzenetetracarboxylic acid molecule $\left(\mathrm{H}_{4} \mathrm{btc}\right)$ has structural features that make it an outstanding candidate for metal-organic hybrid compounds, with four divergent carboxylic acid groups ready to act as binding sites for metal ions.

Finally, the presence of donor solvent molecules such as water, amines, etc., in the vicinity of the carboxylato groups frequently promotes the formation of supramolecular structures through extended hydrogen-bonding networks, sometimes in the form of porous systems having applications in size-selective sorption, host - guest recognition, catalysis, etc. [8-10].

We report here a polymeric structure, serendipitously obtained when looking for something else (see experimental section) which takes advantage of all the above characteristics, viz., $\left[\mathrm{Co}\left(\mathrm{H}_{2} \mathrm{O}\right)_{4}\left(\mathrm{C}_{10} \mathrm{H}_{2} \mathrm{O}_{8}\right)^{2-}\right]_{n}$. $\mathrm{n}\left[\mathrm{Co}\left(\mathrm{H}_{2} \mathrm{O}\right){ }_{6}{ }_{6}^{2+} 8\left(\mathrm{H}_{2} \mathrm{O}\right)\right]$ (I) where $\mathrm{H}_{4}$ btc is benzene-1,2,4,5-tetracarboxylic acid (Scheme).

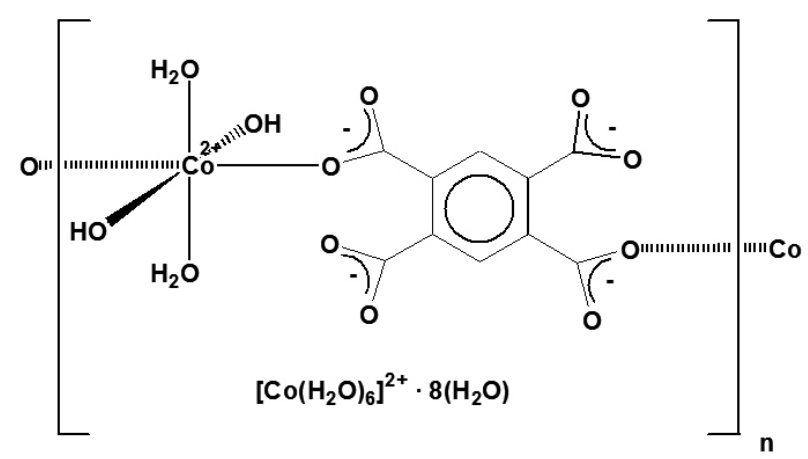

\section{EXPERIMENTAL}

The original (unsuccessful) synthesis looked for a Co-btc-dap (dap = 2,6-diaminopurine) complexes, and the following steps were followed in the procedure: 2,6-Diaminopurine $(0.300 \mathrm{~g}, 2 \mathrm{mmol})$ and cobalt acetate tetrahydrate $(0.498 \mathrm{~g}, 2 \mathrm{mmol})$ were dissolved in water-ethanol $(2: 1 \mathrm{v} / \mathrm{v}, 10$ $\mathrm{ml})$ and the mixture was kept under reflux for $10 \mathrm{~min}$. An aqueous solution $(40 \mathrm{ml})$ of benzene-1,2,4,5-tetracarboxylic acid $(0.508 \mathrm{~g}, 2 \mathrm{mmol})$ and $\mathrm{NaOH}$ $(0.080 \mathrm{~g}, 2 \mathrm{mmol})$ was added to this mixture, which was kept under reflux for another $4 \mathrm{~h}$.

Slow evaporation at room temperature for two weeks yielded two different kinds of single crystals, both of them apt for x-ray diffraction: a majority phase of dap-containing specimens, formulated as $\left[\mathrm{Co}(\mathrm{dap})_{2}\left(\mathrm{H}_{2} \mathrm{O}\right)_{4}\right]\left(\mathrm{C}_{10} \mathrm{H}_{2} \mathrm{O}_{8}\right) \cdot 4 \mathrm{H}_{2} \mathrm{O}$, which have already been analyzed and reported [11] ) and a second, minority crop of dap-free crystals corresponding to the title compound (I).

Single Crystal Study.

Single crystal x-ray data were obtained in a Bruker SMART CCD area detector diffractometer, using the program SMART [12] for data collection and SAINT [13] for cell refinement and data reduction. Absorption corrections were performed using the multi-scan technique implemented in SADABS [13]. The structure was solved using Direct Methods with SHELXS97 [14], refined on $\mathrm{F}^{2}$ with SHELXL97 [14] and validated with PLATON [15] : Finally, all the artwork was produced using SHELXTL [14]. Table 1 presents some crystallographic data of (I); Table 2, selected bond distances and angles. Table 3 presents the most significant $\mathrm{H}$-bonds.

From the eight independent water solvato molecules, only three (O6W O8W) presented full occupancy, the remaining five being highly dispersed and finally modelled in 11 different sites (O9W - O19W) with partial occupancy. Fractions $(\mathrm{O} 14 \mathrm{~W}-\mathrm{O} 19 \mathrm{~W})$, with the smallest o.f.'s were refined isotropically.

$\mathrm{H}$ atoms in fully occupied water molecules, as well as $\mathrm{C}-\mathrm{H}$ 's were found in a difference Fourier, and treated differently in refinement: $\mathrm{C}-\mathrm{H}$ 's were further repositioned in their expected positions and allowed to ride $[\mathrm{d}(\mathrm{C}-$ $\left.\left.\mathrm{H}_{\text {aromatic }} \mathrm{C}\right)=0.95 \AA\right]$, while $\mathrm{O}-\mathrm{H}$ 's were refined with restrained $\mathrm{d}(\mathrm{O}-\mathrm{H})=0.85$ $($ aromatic $\AA(H \cdots H)=1.35(2) \AA$. Those corresponding to water solvates $\mathrm{O} 6 \mathrm{~W}$, $\mathrm{O} 7 \mathrm{~W}, \mathrm{O} 8 \mathrm{~W}$ were kept fixed in the latest cycles of refinement. In all cases, $\left[U(\mathrm{H})=1.2 \times U_{\text {eq }}\right.$ (host). The final difference map showed three main maxima significantly above the rest $\left(1.82,1.55,1.15 \mathrm{e}^{-3}\right)$ at about $0.85 \AA$ from the cations; the rest displayed a rather even peak distribution in the range $\pm 0.50 \mathrm{e} \AA^{-3}$. 
Table 1: Crystal data.

\begin{tabular}{|c|c|c|}
\hline Chemical Formula & \multicolumn{2}{|c|}{$\mathrm{Co}\left(\mathrm{H}_{2} \mathrm{O}\right)_{4}\left(\mathrm{C}_{10} \mathrm{H}_{2} \mathrm{O}_{8}\right) \cdot \mathrm{Co}\left(\mathrm{H}_{2} \mathrm{O}\right)_{6} \cdot 8\left(\mathrm{H}_{2} \mathrm{O}\right)$} \\
\hline$M$ & \multicolumn{2}{|l|}{692.26} \\
\hline Crystal System, Space Group & \multicolumn{2}{|l|}{ Triclinic, $P-1$} \\
\hline \multirow[t]{3}{*}{ Cell parameters } & $a=10.664(4) \AA$ & $\alpha=109.03(3)^{\circ}$ \\
\hline & $b=11.309(4) \AA$ & $\beta=111.724(16)^{\circ}$ \\
\hline & $c=13.321(3) \AA$ & $\gamma=93.16(4)^{\circ}$ \\
\hline$V$ & \multicolumn{2}{|l|}{$1382.3(9) \AA^{3}$} \\
\hline$Z$ & \multicolumn{2}{|l|}{2} \\
\hline Radiation, $\lambda=$ & \multicolumn{2}{|l|}{ Mo $K \alpha, 0.71073 \AA$} \\
\hline$\mu$ & \multicolumn{2}{|l|}{$1.30 \mathrm{~mm}^{-1}$} \\
\hline$T$ & \multicolumn{2}{|l|}{$150 \mathrm{~K}$} \\
\hline Crystal Size & \multicolumn{2}{|c|}{$0.24 \times 0.13 \times 0.13 \mathrm{~mm}$} \\
\hline $\mathrm{T}_{\mathrm{Max}}, \mathrm{T}_{\mathrm{M} \min }$ & \multicolumn{2}{|l|}{$0.85,0.82$} \\
\hline Reflections: measured, indep. with $\mathrm{I}>2 \sigma(\mathrm{I})$ & \multicolumn{2}{|l|}{$11142,5440,4908$} \\
\hline Rint & \multicolumn{2}{|l|}{0.034} \\
\hline Data, restraints, parameters & \multicolumn{2}{|l|}{$5440,60,431$} \\
\hline$R\left[F^{2}>2 \sigma\left(F^{2}\right)\right] w R\left(F^{2}\right), \mathrm{S}$ & \multicolumn{2}{|l|}{$0.037,0.113,1.18$} \\
\hline$\Delta \rho_{\max }, \Delta \rho_{\operatorname{mln}}$ & \multicolumn{2}{|l|}{$1.82,-0.58 \mathrm{e}^{-3}$} \\
\hline
\end{tabular}

Table 2 : Selected bond lengths $(\AA)$

\begin{tabular}{|c|c|c|c|}
\hline Co1-O1W' & $2.0396(18)$ & $\mathrm{Co} 2-\mathrm{O} 2$ & $2.0780(14)$ \\
\hline $\mathrm{Co} 1-\mathrm{O} 1 \mathrm{~W}$ & 2.0494 (17) & $\mathrm{Co} 2-\mathrm{O} 2^{{ }^{i}}$ & $2.0786(14)$ \\
\hline $\mathrm{Co} 1-\mathrm{O} 2 \mathrm{~W}$ & $2.0935(17)$ & $\mathrm{Co} 2-\mathrm{O} 4 \mathrm{~W}^{\prime}$ & $2.0955(16)$ \\
\hline $\mathrm{Co} 1-\mathrm{O} 2 \mathrm{~W}^{\prime}$ & $2.0936(17)$ & $\mathrm{Co} 2-\mathrm{O} 5 \mathrm{~W}^{\prime}$ & $2.1002(16)$ \\
\hline $\mathrm{Co} 1-\mathrm{O} 3 \mathrm{~W}^{\prime}$ & $2.112(2)$ & $\mathrm{Co} 2-\mathrm{O} 4 \mathrm{~W}$ & $2.1417(16)$ \\
\hline $\mathrm{Co} 1-\mathrm{O} 3 \mathrm{~W}$ & $2.116(2)$ & $\mathrm{O} 2^{\prime}-\mathrm{Co} 2^{\mathrm{ii}}$ & $2.0780(14)$ \\
\hline $\mathrm{Co} 2-\mathrm{O} 5 \mathrm{~W}$ & $2.0748(16)$ & & \\
\hline
\end{tabular}

Symmetry codes: (i) $x, y-1, z$; (ii) $x, y+1, z$.

Table 3 : Hydrogen-bond geometry $\left(\AA,{ }^{\circ}\right)$.

\begin{tabular}{|c|c|c|c|c|}
\hline$D-\mathrm{H} \cdots A$ & $D-\mathrm{H}$ & $\mathrm{H} \cdots A$ & $D \cdots A$ & $D-\mathrm{H} \cdots A$ \\
\hline $\mathrm{O} 4 W-\mathrm{H} 4 W A \cdots \mathrm{O} 1^{\prime i}$ & $0.84(1)$ & $1.88(1)$ & $2.647(2)$ & $151(2)$ \\
\hline $\mathrm{O} 5 W-\mathrm{H} 5 W A{ }^{\cdots} \mathrm{O}^{\prime}$ & $0.83(1)$ & $1.95(1)$ & $2.782(2)$ & $176(2)$ \\
\hline $\mathrm{O} 4 W^{\prime}-\mathrm{H} 4 W D^{\cdots} \cdots \mathrm{O} 1$ & $0.84(1)$ & $1.95(2)$ & $2.675(2)$ & $144(2)$ \\
\hline $\mathrm{O} 5 W^{\prime}-\mathrm{H} 5 W C \cdots \mathrm{O} 4^{\mathrm{i}}$ & $0.85(1)$ & $1.88(1)$ & $2.724(2)$ & $178(2)$ \\
\hline $\mathrm{O} 4 W-\mathrm{H} 4 W B \cdots \mathrm{O} 4^{\prime \text { iii }}$ & $0.84(1)$ & $2.01(1)$ & $2.789(2)$ & $153(2)$ \\
\hline $\mathrm{O} 5 W-\mathrm{H} 5 W B \cdots \mathrm{O}^{\prime \text { iii }}$ & $0.84(1)$ & $1.77(1)$ & $2.608(2)$ & $174(2)$ \\
\hline $\mathrm{O} 4 W^{\prime}-\mathrm{H} 4 W C \cdots \mathrm{O} 4^{\text {iv }}$ & $0.84(1)$ & $2.01(1)$ & $2.782(2)$ & $152(2)$ \\
\hline $\mathrm{O} 5 W^{\prime}-\mathrm{H} 5 W D^{\cdots} \mathrm{O}^{\mathrm{iv}}$ & $0.84(1)$ & $1.75(1)$ & $2.590(3)$ & $175(2)$ \\
\hline $\mathrm{O} 1 W-\mathrm{H} 1 W B \cdots \mathrm{O} 6 W$ & $0.84(1)$ & $2.00(1)$ & $2.799(2)$ & $159(2)$ \\
\hline $\mathrm{O} 2 W-\mathrm{H} 2 W A \cdots \mathrm{O} 7 W$ & $0.85(1)$ & $1.93(1)$ & $2.780(2)$ & $177(2)$ \\
\hline $\mathrm{O} 2 W-\mathrm{H} 2 W B \cdots \mathrm{O} 6 W^{v}$ & $0.85(1)$ & $1.90(1)$ & $2.746(3)$ & $174(2)$ \\
\hline $\mathrm{O} 3 W-\mathrm{H} 3 W A \cdots \mathrm{O} 12 W$ & $0.84(1)$ & $2.03(1)$ & $2.865(3)$ & $169(2)$ \\
\hline $\mathrm{O} 3 W-\mathrm{H} 3 W A \cdots \mathrm{O} 14 W$ & $0.84(1)$ & $1.99(2)$ & $2.79(2)$ & $158(2)$ \\
\hline $\mathrm{O} 1 W^{\prime}-\mathrm{H} 1 W D \cdots \mathrm{O} 10 W$ & $0.86(1)$ & $1.81(1)$ & $2.661(3)$ & $175(3)$ \\
\hline $\mathrm{O} 1 W^{\prime}-\mathrm{H} 1 W D \cdots \mathrm{O} 16 W$ & $0.86(1)$ & $2.23(2)$ & $3.076(12)$ & $172(2)$ \\
\hline $\mathrm{O} 2 W^{\prime}-\mathrm{H} 2 W C \cdots \mathrm{O} 17 W$ & $0.85(1)$ & $1.87(1)$ & $2.723(7)$ & $177(2)$ \\
\hline $\mathrm{O} 2 W^{\prime}-\mathrm{H} 2 W C \cdots \mathrm{O} 11 W$ & $0.85(1)$ & $1.90(1)$ & $2.728(3)$ & $163(2)$ \\
\hline $\mathrm{O} 2 W^{\prime}-\mathrm{H} 2 W D \cdots \mathrm{O} 8 W$ & $0.84(1)$ & $1.94(1)$ & $2.773(2)$ & $173(2)$ \\
\hline $\mathrm{O} 3 W^{\prime}-\mathrm{H} 3 W D \cdots \mathrm{O} 13 W$ & $0.85(1)$ & $1.93(1)$ & $2.743(4)$ & $161(2)$ \\
\hline $\mathrm{O} 3 W^{\prime}-\mathrm{H} 3 W D \cdots \mathrm{O} 18 W$ & $0.85(1)$ & $2.09(3)$ & $2.90(3)$ & $159(2)$ \\
\hline $\mathrm{O} 3 W^{\prime}-\mathrm{H} 3 W D \cdots \mathrm{O} 19 W$ & $0.85(1)$ & $2.24(3)$ & $3.08(2)$ & $168(2)$ \\
\hline $\mathrm{O} 6 W-\mathrm{H} 6 W A \cdots \mathrm{O} 12 W^{v}$ & 0.85 & 2.05 & $2.885(3)$ & 168 \\
\hline $\mathrm{O} 7 W-\mathrm{H} 7 W B^{\cdots} \cdots \mathrm{O} 9 W^{v}$ & 0.81 & 2.21 & $2.918(4)$ & 147 \\
\hline $\mathrm{O} 8 W-\mathrm{H} 8 W B \cdots \mathrm{O} 10 W$ & 0.88 & 1.83 & $2.608(3)$ & 147 \\
\hline $\mathrm{O} 1 W-\mathrm{H} 1 W A \cdots \mathrm{O} 3^{\prime v}$ & $0.85(1)$ & $1.85(1)$ & $2.695(2)$ & $169(2)$ \\
\hline $\mathrm{O} 3 W-\mathrm{H} 3 W B \cdots \mathrm{O} 1^{\prime v}$ & $0.86(1)$ & $1.85(1)$ & $2.678(2)$ & $163(2)$ \\
\hline $\mathrm{O} 1 W^{\prime}-\mathrm{H} 1 W C \cdots{ }^{\cdots} 3^{\text {iv }}$ & $0.84(1)$ & $1.90(1)$ & $2.732(2)$ & $167(2)$ \\
\hline $\mathrm{O} 3 W^{\prime}-\mathrm{H} 3 W C^{\cdots} \cdot{ }^{\text {iv }}$ & $0.84(1)$ & $1.86(1)$ & $2.680(2)$ & $164(2)$ \\
\hline $\mathrm{O} 6 W-\mathrm{H} 6 W B \cdots \mathrm{O} 2^{\mathrm{v}}$ & 0.84 & 1.92 & $2.749(2)$ & 170 \\
\hline $\mathrm{O} 7 W-\mathrm{H} 7 W A \cdots \mathrm{O} 4$ & 0.84 & 1.99 & $2.824(2)$ & 169 \\
\hline $\mathrm{O} 8 W-\mathrm{H} 8 W A \cdots \mathrm{O} 4^{\prime \mathrm{vi}}$ & 0.87 & 1.94 & $2.790(2)$ & 168 \\
\hline
\end{tabular}

Symmetry codes: (i) $x, y-1, z$; (iii) $-x+1,-y,-z$; (iv) $-x+2,-y+1,-z+1$; (v) $-x+1,-y+1,-z+1$; (vi) $x, y, z+1$. 


\section{RESULTS AND DISCUSSION}

The independent unit of (I) consists of two Co(II) cations siting in general positions, one fully deprotonated btc anion and eight solvato water molecules, three of which are ordered (with unit occupation factor), and the remaining five appear fairly dispersed in partially occupied sites (Fig.1)

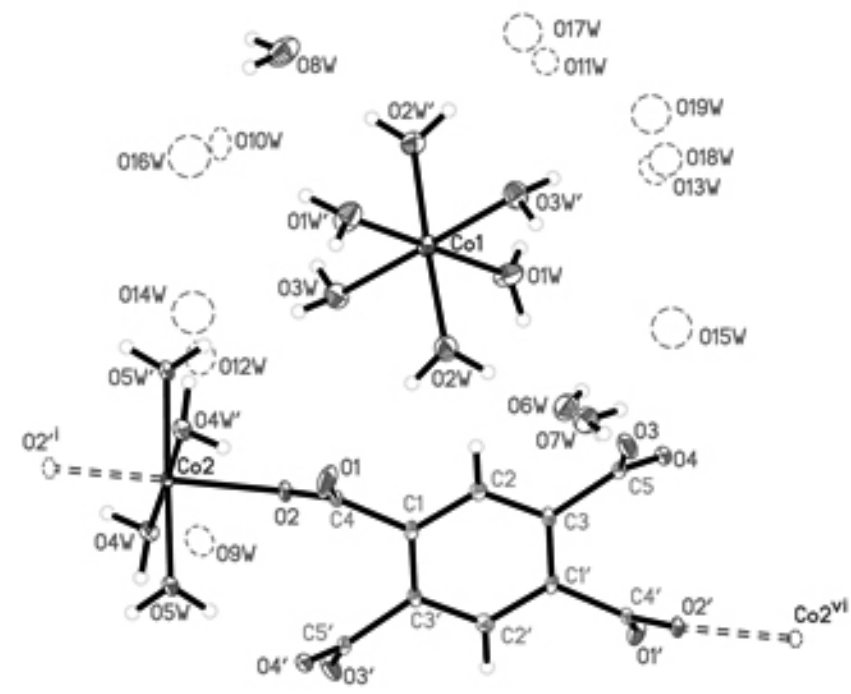

Figure 1. The asymmetric unit of (I), with displacement ellipsoids drawn at a $40 \%$ probability level. Symmetry codes: (i): $x, y-1, z$, (ii): $x, y+1, z$.

One of the two independent Co(II) centres in the structure is surrounded by six water molecules defining isolated $\mathrm{Co}\left(\mathrm{H}_{2} \mathrm{O}\right)_{6}{ }_{6}^{2+}$ cationic octahedra, while the second resides in polymeric chains formed by "beads" of $\mathrm{Co}\left(\mathrm{H}_{2} \mathrm{O}\right)_{4}{ }^{2+}$ planar units, "threaded" by fully deprotonated btc ${ }^{4}$ anions binding through opposite carboxylato groups in a trans fashion. This arrangement defines $\left[\mathrm{Co}\left(\mathrm{H}_{2} \mathrm{O}\right)_{4}(\mathrm{btc})\right]^{2-}$ anionic chains running along [010]. Both types of $\mathrm{CoO}_{6}$ octahedra are fairly regular either in $\mathrm{Co}-\mathrm{O}$ distances (Co1-O span: 2.0386 (16)-2.1156 (18) $\AA$; Co2-O span: 2.0784 (13)-2.1424 (14) $\AA$ ) or in O- $\mathrm{Co}-\mathrm{O}$ angles, as measured by their tight span around ideal values: $\mathrm{O}-\mathrm{Co} 1-\mathrm{O}$, $180(2)^{\circ}, 90(4)^{\circ} ; \mathrm{O}-\mathrm{Co} 2-\mathrm{O}, 180(2)^{\circ}, 90(4)^{\circ}$. The btc anion is basically featureless, with similar, resonant $\mathrm{C}-\mathrm{O}$ bonds in the carboxylato groups and where only a slight departure from the average may be found for the $\mathrm{O} 2-\mathrm{C} 4$, $\mathrm{O} 2$ '-C4' bonds $(<\mathrm{C}-\mathrm{O}>: 1.273(4) \AA)$, slightly longer than the mean of the rest $(<\mathrm{C}-\mathrm{O}>: 1.240(12) \AA)$ probably due to their involvement in coordination

Anionic chains, on one side, and cationic monomers and solvato molecules on the other organize in alternating $2 \mathrm{D}$ structures parallel to $\left({ }^{-} 101\right)$ at a distance $\mathrm{d}-1 / 2$ apart $(\sim 4.80 \AA)$, intra and interconnected by a profuse net of $(\mathrm{O}-\mathrm{H}) \quad$ (... O bonds (Table 3$)$.

Fig 2 shows the $2 \mathrm{D}$ structures defined by the $\left[\mathrm{Co}\left(\mathrm{H}_{2} \mathrm{O}\right)_{4}\left(\mathrm{C}_{10} \mathrm{H}_{2} \mathrm{O}_{8}\right)^{2-}\right]$ chains, having $\mathrm{O} 4 \mathrm{~W}$ and $\mathrm{O} 5 \mathrm{~W}$ as donors and the carboxylato oxygens not involved in coordination as acceptors. The H-bonds involved are those in entries $1-8$ in Table 3; the first four of these are "intra-chain" and provide to the chains internal cohesion, while the remaining four serve to the interchain linkage.

Fig. 3 , in turn, displays the very complex $2 \mathrm{D}$ structure involving the $\mathrm{Co}\left(\mathrm{H}_{2} \mathrm{O}\right)_{6}{ }^{2+}$ octahedra and the (3 ordered and 5 disordered) solvato water molecules. Even if the precise description of the $\mathrm{H}$-bonding scheme is somehow jeopardized by the missing of some $\mathrm{H}$ atoms in the model, those effectively found are enough to assess the high complexity of this substructure. Inspection of the figure suggests a disposition of octahedra forming chains along the [101] direction (In Figure 3, line [A-A], from top to bottom), linked via the few ordered $(\mathrm{O} 6 \mathrm{~W}, \mathrm{O} 7 \mathrm{~W}, \mathrm{O} 8 \mathrm{~W})$ water solvates. Filling the space between these H-bonded chains the more weakly bound, disordered water solvates $(\mathrm{O} 9 \mathrm{~W} \rightarrow$ O19W) serve as "gluing agents". The H-bonds involved are those in Table 3, entries 9 - 24

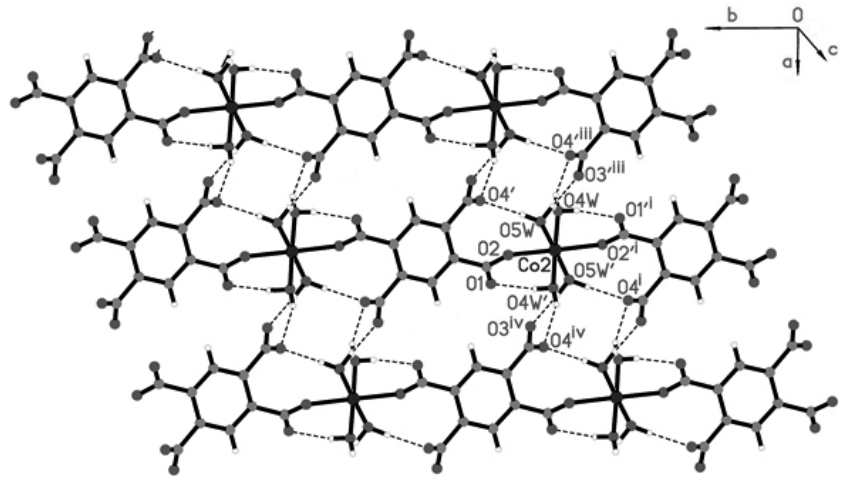

Figure 2. Packing view of (I) showing the H-bonded $2 \mathrm{D}$ anionic substructure. Symmetry codes: (i) $\mathrm{x}, \mathrm{y}-1, \mathrm{z}$; (iii) $-\mathrm{x}+1,-\mathrm{y},-\mathrm{z}$; (iv) $-\mathrm{x}+2,-\mathrm{y}+1$, $-\mathrm{z}+1$.

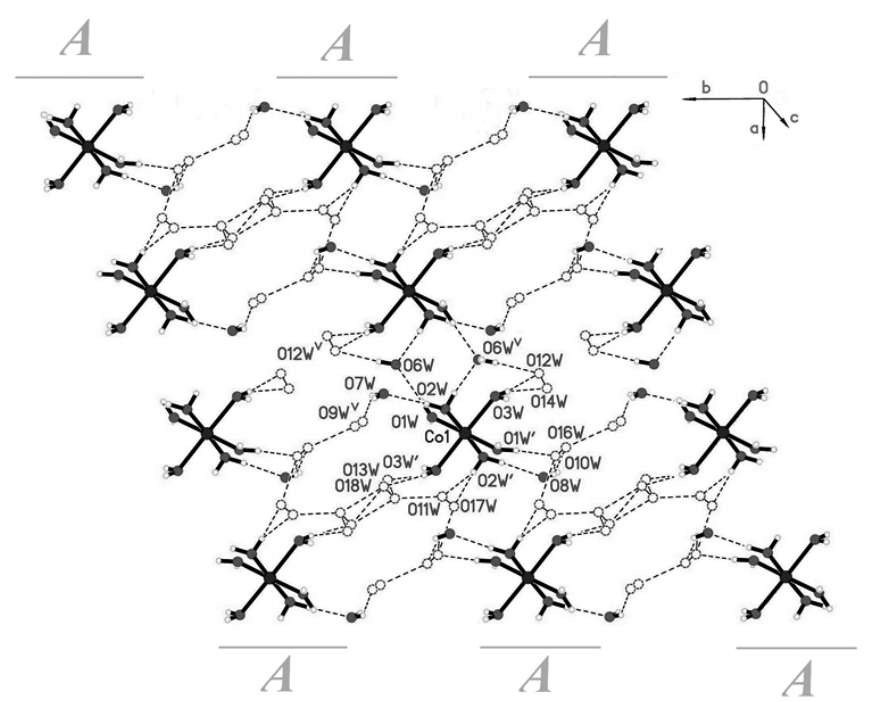

Figure 3. Packing view of (I) showing the H-bonded $2 \mathrm{D}$ cationic substructure. Symmetry codes: (v) $-\mathrm{x}+1,-\mathrm{y}+1,-\mathrm{z}+1$.

Finally, the two types of planar arrays stack in alternating fashion along [010], interacting through the group of bonds presented in Table 3 as entries 25 - 31. Fig. 4 shows a projection of the structure down [101], which clarifies much of what described so far: the (covalent) anionic chains are shown running parallel to the projection plane, top to bottom; perpendicular to them and coming out of the plane the cationic chains, inter-linked by H-bonds involving the disordered water solvates; finally, the cross link between both planar arrays can be clearly seen.

A detailed analysis of the results evidenced a number of singularities in the structure: firstly, a striking non-crystallographic inversion symmetry around each molecular group; secondly, the fact that even if a search in the V5.33 version of the CSD [16] had shown no cell coincidences with the one in (I), almost an identical motive had already been reported in three previous publications, viz., Poleti \& Karanovic, 1989 [17] (IIa); Robl \& Hentschel, 1991[18] (IIb) and more recently, in Zeller et al., 2005 [19] (IIc), sharing among them identical triclinic cells in P-1, with half the volume of the one in the present report, viz., $\mathrm{V}_{\text {(II) }} \sim 1 / 2 \mathrm{~V}_{\text {(I) }}$ The structures (IIa, IIb,IIc) present (slight) differences in their solvato content $(7.36,8.00$ and 7.20 water molecules per formula unit, respectively) as well as in the disorder shown, both in solvates as in the cationic groups. 


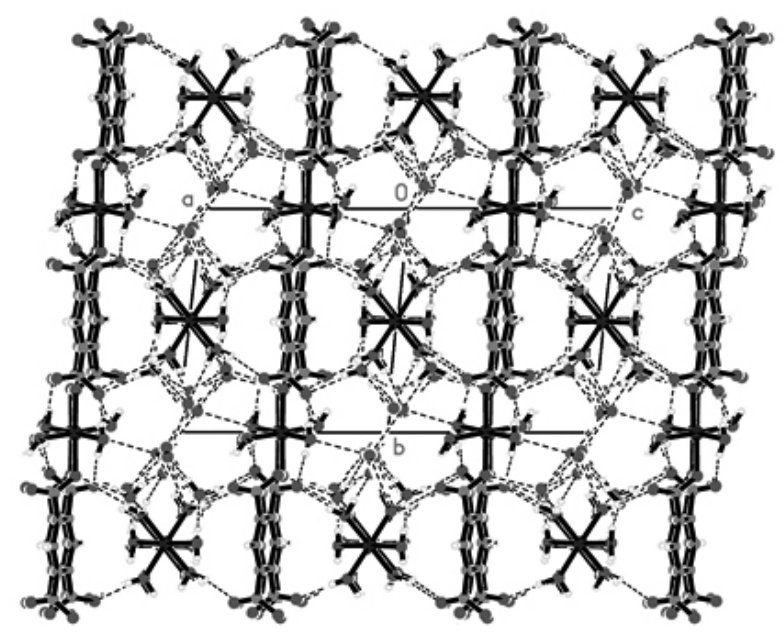

Figure 4. Packing view of (I) showing in projection both types of $\mathrm{H}$-bonded 2D substructures, as well as their interactions.

In these structures the Co(II) cations and the btc anion are strictly located at inversion centres, something which in (I) is (as already stated) only a striking non crystallographic symmetry. The degree of certainty in $\mathrm{H}$ positioning in the three reported structures is variable, but in general terms agree with what found for (I), with coordinated water molecules being well defined; solvates, instead are much less so. The $\mathrm{V}_{\text {(I) }} \sim 2 \times \mathrm{V}_{\text {(II) }}$ volume ratio strongly suggested the possibility of a (I) $\rightarrow$ (II) transformation between both cells, and in fact this relationship between the direct vectors in (I) $\{\mathrm{A}, \mathrm{B}, \mathrm{C}\}$ and those in (II) $\{\mathrm{a}, \mathrm{b}, \mathrm{c}\}$ does exist, viz.:

$\{a, b, c\}=M \times\{A, B, C\}$,

the transformation matrix being $\mathrm{M}=(-0.5,0,-0.5 ;-0.5,0,0.5 ; 0.5,1,0.5)$, with a Det $=2$, as required by the volume relationship.

For our comparison we have chosen (IIb) as the representative structure of the lot, since, as (I), it does not show any disorder in the non-solvato part of the structure. When the M transformation is applied to the cell contents in (I), an almost exact replica of the cationic and anionic part in (IIb) is obtained (for convenience we shall call this transformed structure (IId) ), with only some misfit in the water solvates (Fig. 5). As an example we quote the cell parameters in (IId)/(IIb) order: $\mathrm{a}=6.819$ (2)/6.864 (1) $\AA ; \mathrm{b}=9.954(2) / 10.000$ (2) $\AA ; c=10.892(6) / 10.932(2) \AA ; \alpha=92.80$ (3)/93.00 (2) ${ }^{\circ} ; \beta=104.52$ (4)/104.86 $(1)^{\circ} ; \gamma=103.57(6) / 103.59(1)^{\circ}, V=691.2(5) / 699.9(14) \AA^{3}$. Considering that no correction for cell shinkage has been made (Cell measurement temperature for $(\mathrm{I})=(\mathrm{IId})$ : $150 \mathrm{~K}$; for (IIb): $295 \mathrm{~K}$ ) the matching is extremely accurate.

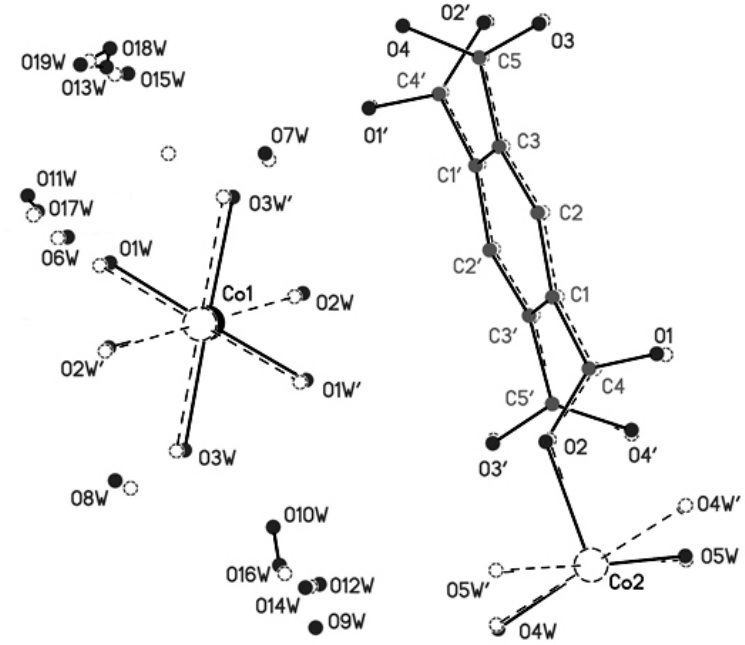

Figure 5. A schematic view of the overlapping structures (IId)/(IIb) in full/ dashed lining and balls.
Application of the transformation to the indices in the $\mathrm{HKL}_{(\mathrm{I})}$ data set splitted the reflections into two subsets, one of them with integer indices and stronger reflections, coinciding with the Bragg peaks of the small cell (IId) and the remaining one with non-integer values in some of them and weaker intensities. The latter subset corresponds to the superstructure in (I), responsible of the symmetry rupture. A few descriptors of the two sets follow, in the order in which they have been described: (N: 2867/2934; $\left\langle\mathrm{F}^{2}\right\rangle$ : 1517.6/140.8; $<\mathrm{S}\left(\mathrm{F}^{2}>\right): 80.4 / 10.7 ;<\left(\mathrm{F}^{2} / \mathrm{S}\left(\mathrm{F}^{2}\right)>15.1 / 10.3\right)$

The final confirmation of the extremely small discrepancies between the two structure types was provided by a refinement of the transformed model (IId) using the data subset with integer indices. After some polishing of the $\mathrm{H}$ atoms and disordered solvates, the final discrepancy index ended up being $\mathrm{R}=$ 4.02 , better than the one reported for (IIa) and only slightly larger than those reported for (IIb,IIc) using the original data sets.

We can conclude that even if the present work does not provide any relevant extra details to those already known for the polymeric structure (solutions (I) and (IIa,IIb,IIc) are technically indistinguishable from a chemical point of view), it is interesting in crystallographic terms since it reflects, through a symmetry breakdown, an intrinsic lability of the system in the solid state, already suggested by the difficulties in refinement found in the three previous structural studies. In (IIa,IIb,IIc) this is further evidenced by the different kinds of disorder found, either in the solvates or the cationic group; in the present case of (I), this slight modifications have been extended to the individual molecular symmetries.

When exploring the possible reasons for the appearance of such an odd phase in a seemingly well established structure, marginal perturbative effects eventually introduced during crystallization by the presence of dap in solution (see experimental section) can not be ruled out.

\section{ACKNOWLEDGEMENTS}

We acknowledge the Spanish Research Council (CSIC) for providing us with a free-of-charge license to the CSD system (Allen, 2002). We also thank funding by project Fondecyt 1120125.

\section{Supplementary Data}

CCDC 904672 contains the supplementary crystallographic data for this paper. These can be obtained free of charge from The Cambridge Crystallographic Data Centre via www.ccdc.cam.ac.uk/data_request/cif.

\section{REFERENCES}

1. M. Eddaoudi, D.B. Moler, H. Li, B.Chen, T.M. Reineke, M. O'Keeffe ,O.M.Yoghi ACC Chem. Res. 34,319, (2001).

2. Y.B. Go, X. Wang, E.V. Anokhina and A.J. Jacobson Inorg. Chem. 44,8266, (2005).

3. Z. Shi, G. Li , L. Wang, L. Gao, X.Chen, J. Hua and S.Feng S Cryst. Growth Des. 4, 25, (2004).

4. M.Eddaoudi, J.Kim, N. Rosi, D.Vodak, J. Wachter, M. O'Keeffe, O.M. Yaghi .Science, 295, 469, (2002).

5. J.L.C. Roswell, OM. Yaghi. Microporous Mesoporous Mater. 73,3, (2004).

6. Q. Wang, X. Wu, W. Zhang, T. Sheng, P. Lin, J. Li. Inorg. Chem.38, 2223, (1999).

7. S.H. Whitlow. Inorg. Chem. 12, 2286, (1973).

8. P.K. Coughlin, S.J. Lippard. J. Am. Chem. Soc. 106, 2328, (1984).

9. E. Colacio, J.M. Dominguez-Vera, JP. Costes, R. Kivekas, JP. Laurent, J. Ruiz, M. Sundberg Inorg. Chem. 31,774, (1992).

10. E. Colacio, J.M. Dominguez-Vera, R. Kivekas, J. Ruiz . Inorg.Chim. Acta. 218,109, (1994).

11. A.M. Atria, M.T. Garland, R. Baggio. Acta Cryst. C67, m275, (2011).

12. Bruker SMART-NT. Siemens Analytical X-ray Instruments Inc., Madison, Wisconsin, USA. (2001).

13. Bruker SAINT-NT. Version 6.22A (including SADABS).Siemens Analytical X-ray Instruments Inc., Madison, Wisconsin, USA. (2002).

14. G.M. Sheldrick .Acta Cryst. A64,112, (2008).

15. A.L. Spek. Acta Cryst. D65,148, (2009).

16. F. H. Allen, Acta Cryst. B58, 380, (2002).

17. D. Poleti, L.J.Karanovic. Acta Cryst.,C45,1716, (1989).

18. C. Robl, S. Hentschel . Mater.Res.Bull.,26,1355,(1991).

19. M. Zeller, A.R. Chema , P.S. Szalay ,A.D. Hunter J.Chem.Cryst.35,433, (2005). 